\title{
Thoughts and Practices on Improving the Quality of Graduation Design in Applied Undergraduate Colleges
}

\author{
Jingfeng He \\ School of Science, \\ Xijing University \\ Xi'an, Shaanxi, 710123, China
}

\begin{abstract}
In view of the problems of low quality and inconsistent direction between graduation thesis and training direction in applied undergraduate colleges and universities, Xijing University aims at improving the selection of graduation topics, the quality evaluation and inspection links of graduation papers, and the formulation of graduation thesis evaluation system, so as to improve the level of graduation thesis. Through the spot check results of graduation papers of graduates in the past three years, the quality of graduation thesis has been improved obviously.
\end{abstract}

Keywords-Applied type; undergraduate college; graduation design; thinking and practice

\section{INTRODUCTION}

In 2015, Premier Li Keqiang pointed out in the government report that it is necessary to "guide some local undergraduate colleges to shift to application"[1]. The transformation of local colleges and universities to application has become a hot topic in the current reform of higher education in China, and it is also an important proposition of the times in the development of higher education. As the most important practical link to test and improve graduates' ability to analyze and solve problems, the importance of graduation thesis is conceivable. The new applied undergraduate colleges and universities themselves have not been running a school for a long time, the experience of transformation and upgrading is limited, and there will inevitably be many problems in the management of graduation papers, which urgently needs the active exploration and practice of the vast number of new applied undergraduate colleges and universities. Innovate and improve management methods, strive to improve the management level of graduation thesis [2].

\section{THE MAIN FACTORS AFFECTING THE QUALITY OF GRADUATION THESIS (DESIGN) IN APPLICATION-ORIENTED UNIVERSITIES}

There is a gap between the graduation design topic and the talent training goal. Due to the large enrollment of the applied undergraduate colleges and the high student level, the application ability of the instructors is uneven. Some of the topics are not targeted, and the depth and breadth are not enough. Some of the topics are repeated, the technology is outdated, and lack of innovation. Some of the research foundations and conditions are not sufficient, and it is difficult to achieve the expected goals. Some of the selected topics are not clear, the ideas are not clear, and it is difficult to form materialized results[3].

\section{A. There is a Gap between Graduation Design Topics and Talent Training Goals}

Because of the large enrollment scale of applied undergraduate colleges and universities, the students are relatively high, the ability of guiding teachers to apply is uneven, some of the topics are not targeted, and the depth and breadth of the topics are not enough. Some of the topics are repeated, the technology is old, and lack of innovation[4].Some topics have been studied on the basis of insufficient conditions, which make it difficult to achieve the expected goals. Some topics are not clear objectives, ideas are not clear, difficult to form materialized results.

\section{B. There is a Big Conflict between Graduation Design Time and Student Employment.}

At the stage of graduation design implementation, students are faced with practice and employment, some students do not know the importance of graduation design, put forward the requirements of early practice and employment, but graduation design project and internship, employment relevance is not great. Sometimes it is impossible to do both at the same time. The quality of graduation design has been seriously affected by the insufficient energy and initiative of the students, the neglect of management by the guidance teacher and the inability of the guidance time to guarantee the quality of graduation design[5].

\section{There is a Big Gap between the Quality of Graduation}

Design and the Certification Requirements for Engineering Education

Some graduation design papers in English and Chinese abstract, keywords, references, charts, non-standard format, the overall workload is small, the design is only at the level of the selection of components, but to the system scheme design, software and hardware design, data processing and other important and substantive content involved less. Some graduation design papers lack of theoretical analysis, there is a phenomenon that the length of the paper is similar to the product specification. Part of the graduation design lack of software, hardware and system debugging links, hardware 
circuit and software program correctness, reliability can't be verified. Some graduation design papers are just phenomena, a brief description of theories and methods, lack of feasibility analysis, experimental data and application results, and the structure of the thesis is incomplete[6].

\section{Graduation Design Quality Evaluation Standards are not Strictly Enforced}

Application-oriented colleges and universities attach great importance to graduation rate and employment rate, while some majors will ignore the achievement of graduation design quality and graduation ability. Although there are relevant requirements and quality evaluation standards for graduation design, but the maneuverability is not strong, the monitoring efforts for topics for examination, opening questions, design process and other links are insufficient, graduation papers are reviewed, the defense is not strict, and the score evaluation is arbitrary. As a result, there is a big gap between the actual quality of graduation design and graduation requirements.

Graduation thesis (design) work involves the participation of teachers and students, implementation conditions and teaching management, which are also the main factors affecting the quality of graduation thesis (design) of applied undergraduate colleges. Instructors and students are key subjects in the implementation of graduation thesis (design) and are the main quality influencing factors. The faculty is one of the shortcomings of the healthy development of applied undergraduate colleges. Not only is the number insufficient, but also the young teachers with medium and low titles, and the proportion of senior titles and doctoral teachers is low. On the one hand, the instructor undertakes heavy teaching work, and has no more energy and time to guide students' graduation thesis (design). On the other hand, it also needs to strengthen its own scientific research level, limited guidance ability and poor guidance effect. This may further lead to the teacher's slack in the work of the thesis (design). Compared with other ordinary undergraduate college students, students in applied undergraduate colleges have certain gaps in their learning ability and comprehensive quality[7]. In addition, they are not affected by factors such as employment and postgraduate examinations in the graduation season, and they cannot fully devote their graduation thesis (In the design), there are thoughts that have passed.

Developing a thesis (design) requires a corresponding teaching resource guarantee. In recent years, the hardware environment of applied undergraduate colleges has been improved to some extent, but there is still much room for improvement. The basic teaching conditions such as experimental practice (training) space, instrument and equipment (set), professional computer room (software), literature digital resources, and off-campus joint construction base can't fully meet the needs of graduation thesis (design) work, and need to increase Investing to create conditions for improving the quality of graduation thesis (design)[8]. At present, the teaching management of graduation thesis (design) in applied undergraduate colleges is still at a low level, and no effective quality assurance and monitoring system has been established. Due to the limited management staff, most of the applied undergraduate colleges do not have a special graduation thesis (design) work management organization, and the existing management personnel are mostly full-time teachers. The whole management process may be the issuance of documents and papers. In terms of performance management, there is no implementation of process management and quality monitoring of important links.

\section{Corrective MEASURES FOR GRADUATION DESIGN OF APPLIED UNDERGRADUATE COLLEGES}

Based on the above analysis, we summarize the main reasons that affect the quality of graduation design. Fundamentally speaking, the above problems are mainly due to the imbalance between teaching, learning and management. Based on this, we propose the following corresponding solutions.

\section{A. Improving the Access Conditions for Graduation Design}

In terms of students, it is necessary to improve the access conditions for graduation design, and only require that all the credits (including compulsory courses, elective courses and practical courses) stipulated in the training program be qualified to enter the graduation design. This will restrict some lazy students from the source, greatly improving students' emphasis on graduation design. In terms of teachers, teachers with graduation design must have certain professional practice experience and a complete professional knowledge structure, which will undoubtedly provide guarantee for improving the quality of students' graduation design. At the same time, it is necessary to strengthen the education of teachers' morality and vocational education so that teachers with graduation design can really take responsibility.

\section{B. Strict Screening of Graduation Design Topics}

Before the question is issued, specific requirements should be put forward for the graduation design questions given by the instructor. From the perspective of teachers, we should try to improve the scientific and interesting nature of the topic selection, so as to improve the enthusiasm of students to choose topics and do the exercises. After the question is issued, the dean and the head of the department should strictly review the subject. Only the questions that have passed the review can be selected by the students. This avoids the problem that the problem is not conducive to the graduation design work. In order to further improve the students' attention to the graduation design process, we also try to improve the practicality of the graduation design topic, and integrate the graduation design topic with the teacher's scientific research or engineering project, which can form the project into several small topics. Let the students participate, so that students recognize the research significance of the subject, they will be full of expectations for the research results of the subject, thus greatly improving the subjective initiative of students to do graduation design. Some schools are too eager to improve the pass rate of their graduation design, so that they can relax the requirements of graduation design. The result of this will affect the overall style of graduation design.

\section{Emphasis on Mid-Term Defense and Strict Process Management}

In the mid-term reply session, each student is required to participate. Otherwise, the final graduation essay will be 
cancelled. At the same time, the score of the mid-term defense will be counted as $15 \%$ of the graduation design. Through the introduction of the graduation design management system, the school manages all aspects of the graduation design and strictly controls the entire process, so that every step of the graduation design process is well documented. Through the implementation of these measures, students pay more attention to graduation design. At the same time, we also intend to improve the evaluation criteria of the instructor review and mutual evaluation of graduation design. If the previous evaluation is unqualified, we must stop the evaluation of the next link, which makes the graduation design process interlocking. The responsibilities of the executives at each stage are clear, which is undoubtedly very helpful in improving the quality of the graduation design.

\section{Improving the Paper's Mutual Evaluation and Check System}

After many discussions and communication, the college has formulated the evaluation criteria for graduation design. At the same time, it also considers the possibility of implementing blind evaluation of teachers outside the school, which can better reflect the principles of openness, fairness and justice, and help to improve the quality of graduation design. Achieve the stated goals of talent development. By carrying out the operation of checking the weight and the readability of the paper, in addition to perfecting the check system, many of the phenomenon of copying and copying are in addition to the "original shape", and the readability of the article is evaluated to prevent students from Reducing the copy ratio also reduces the readability of the paper. This requires students to learn from the information on the Internet, and to fully understand the information, to turn this information into their own language, and deepen their understanding and understanding of related fields.

\section{1) Requirements for Instructors}

a) To ensure the quality of the graduation design, the number of students per instructor is no more than 8 students. The instructor's guidance time for the student is not less than 5 hours per week. Instructors can use face-to-face guidance, online design of graduation design management system and new media communication (WeChat, QQ, email) and other guidance methods, and regularly organize students to conduct seminars.

b) The instructor should be a teacher, teach and educate people, strictly ask students, and be familiar with these rules. We should always insist on putting the cultivation of students first, and avoid the phenomenon of laissez-faire or heavy use and light cultivation.

c) Instructors should pay attention to the students' independent work ability, analytical problem-solving ability, innovation ability training and basic scientific research methods, focus on inspiration and guidance, and mobilize students' enthusiasm and creativity. Teachers with research projects can choose excellent students to intervene in advance. d) The instructor should provide the necessary experimental (test) equipment, software, and location for the student.

2) Requirements for students

a) Students should study hard, be diligent in practice, be brave in innovation, and work together. Respect teachers, humbly accept teachers and relevant engineering and technical personnel, regularly report on work progress, and submit staged results.

b) After the opening report is approved, the students should immediately carry out the research work according to the proposed plan and plan, carry out the software and hardware design, experiment, debugging and other work according to the design plan; submit the graduation design related materials in time according to the regulations.

c) Adhere to academic ethics, independently complete the prescribed tasks, do not falsify, and plagiarize or copy other people's results.

\section{CONCLUSION}

Xijing College has improved the quality of graduation thesis by rigorously planning the scope of the graduation design and strictly implementing the mid-term inspection and graduation defense. In recent years, the quality of the thesis has been improved. The 2018 undergraduate audit evaluation was confirmed by experts.

\section{REFERENCES}

[1] Lin Zhifen, Lin Siwei, Qiu Yanzhen, Huang Juwen, Chen Ling. The Influence of Scientific Research Projects on the Topic Selection and Quality of Undergraduate Graduation Thesis[J].High Teaching Journal, 2019(06):191-193.

[2] Wang Xinxin, He Pengfei. Research on the teaching mode of undergraduate graduation design [J]. Science and Education Wenhui (first issue), 2019 (03): 63-64.

[3] Gao Yang, Jin Ying. Exploration of improving the quality of undergraduate thesis under the background of engineering education professional certification [J]. Heilongjiang Education (Higher Education Research and Evaluation), 2019 (03): 67-68.

[4] Li Shuo, Zhang Yanqun. Analysis of how to do a good job in undergraduate thesis (design) [J]. Caizhi, 2019 (07): 58.

[5] LI Huidi, ZHENG Yumei. Analysis of Graduation Thesis Writing in Local Undergraduate Colleges[J].Journal of Xingtai University, 2019, 34(01):183-185.

[6] Gao Yanli. Thoughts and actions to improve the quality of graduation design papers[J]. Education and Teaching Forum, 2019(09): 219-220.

[7] Wang Fang, Zhou Cuiji, Liu Tianqi, Chen Wensheng. Opportunities and Challenges of College Students' Innovation and Entrepreneurship under the Cooperation of Schools and Enterprises[J]. Education and Teaching Forum, 2019(09): 26-27.

[8] Li Keqin, Zhang Xiaofeng, Su Binghua, Wang Lili. Research and Practice of the Applied 1+2+7 Graduation Design Pattern Based on the Combination of Production and Education[J]. Education and Teaching Forum, 2019(09): 137-138. 